\title{
FOUR Score sebagai Alternatif dalam Menilai Derajat Keparahan dan Memprediksi Mortalitas pada Pasien Cedera Otak Traumatik yang Diintubasi
}

\author{
Prananda Surya Airlangga, Hamzah Hamzah, Dhania A Santosa, Andri Subiantoro \\ Departemen Anestesiologi \& Reanimasi FakultasKedokteran Universitas Airlangga-RSUD Dr. SoetomoSurabaya
}

\begin{abstract}
Abstrak
Skala yang mengukur koma yang ideal seharusnya bersifat linear, reliabel, valid, dan mudah digunakan. Berbagai macam skala telah dikembangkan dan divalidasi untuk mengevaluasi tingkat kesadaran secara cepat, derajat penyakit, dan prognosis terhadap morbiditas maupun mortalitas. Glasgow Coma Scale (GCS) merupakan alat pemeriksaan tingkat kesadaran yang paling sering digunakan dan dijadikan gold standard, namun GCS mempunyai keterbatasan karena pasien yang diintubasi tidak dapat dinilai komponen verbal. Full Outline of UnResponsiveness (FOUR) score dikembangkan untuk mengatasi berbagai keterbatasan GCS. Pemeriksaan FOUR score adalah skala penilaian klinis dalam penilaian pasien dengan gangguan tingkat kesadaran. FOUR score lebih sederhana dan memberikan informasi yang lebih baik, terutama pada pasien cedera otak traumatik yang diintubasi. Hasil penelitian menunjukkan bahwa GCS dan FOUR score memiliki nilai prediksi yang tinggi tidak hanya kematian pada pasien trauma tetapi juga luaran pada pasien yang dipulangkan. Studi multicentre menunjukkan FOUR score dan GCS tidak berbeda dalam memprediksi kematian di rumah sakit. Studi tersebut menyarankan bahwa FOUR score dapat menjadi alat diagnostik yang lebih baik untuk menilai refleks batang otak dan pola pernapasan. Namun penelitian lain didapatkan juga hasil yang bertentangan antara GCS dan FOUR score dalam prediksi luaran pasien. Adanya kontradiksi tersebut menunjukkan perlunya dilakukan lebih banyak studi. Oleh karena itu, telaah literatur ini dilakukan dengan tujuan untuk membandingkan skor GCS dan FOUR dalam memprediksi mortalitas pasien trauma.
\end{abstract}

Kata kunci: Cedera Otak Traumatik (COT), FOUR Score, GCS, mortalitas

JNI 2020, 9 (3): 199-205

\section{FOUR Score as an Alternative in Assessing the Degree of Severity and Predicting Mortality in Intubated Traumatic Brain Injury Patients}

\begin{abstract}
The ideal consciousness scoring scale must be linear, reliable, valid, and user-friendly. There is a need to develop and validate a scale to quickly evaluate the level of consciousness, the severity of the disease, and the prognosis of morbidity and mortality. Glasgow Coma Scale (GCS) is the most commonly used tool to assess the level of consciousness and is considered the gold standard. However, GCS has several limitations, such as inability to evaluate verbal components in intubated patients. To overcome these challenges, researchers developed the Full Outline of UnResponsiveness (FOUR) score. FOUR scores is a clinical grading scale to assess the altered state of consciousness. FOUR scores is simpler and able to provide better information, especially in intubated-traumatic brain injury (TBI) patients. Some studies showed that GCS and FOUR scores have the high predictive value in predicting not only the mortality of trauma patients but also the outcome of discharged patients. A multicentre study showed that FOUR scores and GCS do not differ in predicting inpatient mortality. This study suggested that the FOUR scores could be a better diagnostic tool for assessing brainstem reflexes and breathing patterns. Unfortunately, some studies have found conflicting results between GCS and FOUR scores in predicting patient outcomes. These contradictions suggest the need to conduct more studies. Therefore, this literature review will compare GCS and FOUR scores in predicting mortality of TBI patients.
\end{abstract}

Key words: FOUR Score, GCS, mortality, Traumatic Brain Injury (TBI)

JNI 2020, 9 (3): 199-205

This article is licensed under a

Creative Commons Attribution-NonCommercial-ShareAlike 4.0 International License.

CPrananda Surya Airlangga, Hamzah Hamzah, Dhania A Santosa, Andri Subiantoro

(2020) under the CC-BY-NC-SA license 


\section{Pendahuluan}

Cedera otak traumatik (COT) adalah penyebab utama kematian dan kecacatan pada orang dewasa muda di seluruh dunia dan terlibat dalam hampir setengah dari semua kematian akibat trauma. Sebagian besar penderita berasal dari negara berpenghasilan rendah dan menengah. Selain kematian, cedera otak traumatik dapat menyebabkan kecacatan, menghancurkan masa depan dan keluarga, serta biaya sistem rumah sakit dan komunitas yang sangat besar terkait rehabilitasi dan perawatan jangka panjang individu ini. Menghadapi tantangan kesehatan global saat ini, memprediksi prognosa yang akurat dan outcome awal tidak hanya akan memfasilitasi pengambilan keputusan klinis, tetapi juga meningkatkan konseling pasien dan memungkinkan alokasi sumber daya yang rasional. ${ }^{1}$

Glasgow Coma Scale (GCS) telah dianggap sebagai instrumen standar untuk klasifikasi, penilaian, dan prognosis pasien dengan cedera otak traumatik. Ini adalah komponen utama dari skor trauma yang umum digunakan, serta banyak model prognostik GCS dalam perawatan trauma, sejumlah keterbatasan telah diidentifikasi diantaranya variabilitas antar pengamat, kurangnya COT. Terlepas dari meluasnya penggunaan evaluasi refleks batang otak, dan ketidakmampuan untuk mendapatkan respons verbal dari pasien yang diintubasi. ${ }^{2}$ Untuk mengatasi kelemahan GCS, skala alternatif telah diperkenalkan yaitu Full Outline of UnResponsiveness (FOUR). Akronim ini mencerminkan jumlah komponen (respons mata, respons motorik, refleks batang otak, dan pernapasan), serta skor maksimum pada setiap komponen. Skala FOUR memiliki beberapa keunggulan dibandingkan GCS diataranya adalah memberikan lebih banyak rincian neurologis (termasuk refleks batang otak, reflek mata, pola pernapasan, dan dorongan pernapasan), Skala ini juga mengidentifikasi berbagai tahap herniasi, memfasilitasi deteksi sindroma locked-in dan keadaan vegetatif, dan tidak termasuk respons verbal yang oleh karena itu skala ini mungkin memiliki nilai prognostik yang lebih tinggi untuk pasien yang diintubasi di unit perawatan intensif (ICU). Skala FOUR telah divalidasi pada penggunaanya secara klinis untuk pasien di negara maju. ${ }^{3,4}$

\section{Glasgow Coma Scale (GCS)}

Salah satu metode yang paling umum digunakan untuk mengetahui tingkat kesadaran sesorang yaitu Glasgow Coma Scale (GCS). GCS pertama kali didefinisikan oleh Sir Graham Tisdale dan Bryan Jennet tahun 1974. Skor GCS dapat digunakan untuk menilai status neurologis dan derajat keparahan disfungsi otak termasuk cedera kepala. ${ }^{5}$ Sejak dipublikasikan pertama kali, GCS menjadi skala yang paling sering digunakan tidak hanya di kalangan spesialis saraf atau bedah saraf tetapi di luar bidang tersebut, walaupun memiliki beberapa keterbatasan. ${ }^{5}$ Total skor GCS digunakan untuk mengelompokkan pasien ke dalam beberapa kategori sehingga protokol manajemen dapat dirancang dan luarannya dapat lebih baik. Skor total 13-15 menunjukkan cedera otak ringan, 9-12 cedera otak sedang dan 3-8 cedera otak berat. Ada tiga parameter yang digunakan yaitu membuka mata, respon verbal dan respon motorik. Nilai maksimum (normal) dari masing-masing parameter adalah membuka mata/eye $(E)=4$, respon motorik terbaik $(M)=6$, dan respon verbal $(\mathrm{V})=5 .{ }^{6}$

Beberapa kelemahan yang terdapat pada penilaian GCS diantaranya, pada pasien yang diintubasi, komponen verbal tidak dapat dinilai dan kurang berguna pada $20-48 \%$ pasien. Demikian juga pada pasien yang mengalami afasia, komponen verbal tidak dapat dinilai sehingga memengaruhi hasil akhir. GCS hanya menilai orientasi, yang dengan mudah menjadi abnormal pada pasien yang mengalami agitasi dan delirium. GCS tidak memiliki indikator klinis seperti refleks batang otak abnormal, perubahan pola napas, dan kebutuhan akan ventilasi mekanik yang dapat mencerminkan beratnya penurunan kesadaran. GCS juga tidak mampu mendeteksi perubahan minimal pemeriksaan neurologis. Penggunaan sedasi pada sebagian besar pasien di ruang intensif juga dapat mempengaruhi ketiga komponen GCS. ${ }^{7}$ 
Full Outline of Unresponsiveness (FOUR) Score FOUR (Full Outline of Unresponsiveness) score pertama kali dikembangkan oleh Wijdicks pada tahun 2005 dan diterapkan di ruang intensif Mayo Clinic Rumah Sakit Saint Mary sebagai alternatif terhadap penggunaan skor Glasgow Coma Scale (GCS). Skor ini dikembangkan untuk mengatasi berbagai keterbatasan yang dimiliki GCS. FOUR score memberikan lebih banyak informasi dengan adanya empat komponen penilaian yang

Tabel 1. Perbandingan FOUR Score dan $\mathrm{GCS}^{2}$

\begin{tabular}{|c|c|c|}
\hline FOUR Score & \multicolumn{2}{|c|}{ GCS } \\
\hline Respon mata & & pon Membuka Mata \\
\hline $\begin{aligned} 4= & \text { Kelopak mata terbuka atau pernah terbuka } \\
& \text { dan mengikuti arah atau berkedip oleh } \\
& \text { perintah }\end{aligned}$ & $4=$ & Spontan \\
\hline $\begin{aligned} & 3= \text { Kelopak mata terbuka namun tidak mengi- } \\
& \text { kuti arah }\end{aligned}$ & $3=$ & Dengan perintah verbal \\
\hline $2=\begin{array}{l}\text { Kelopak mata tertutup namun terbuka jika } \\
\text { mendengar suara keras }\end{array}$ & $2=$ & Dengan nyeri \\
\hline $\begin{aligned} & 1= \text { Kelopak mata tertutup namun terbuka oleh } \\
& \text { rangsang nyeri }\end{aligned}$ & $1=$ & Tidak ada respon \\
\hline $\begin{aligned} & 0= \text { Jika kelopak tetap tertutup dengan rangsang } \\
& \text { nyeri }\end{aligned}$ & & torik \\
\hline Respon motorik & $6=$ & Menurut perintah \\
\hline $\begin{aligned} & 4= \text { Ibu jari terangkat, atau mengepal, atau tanda } \\
& \text { "damai" (peace sign) }\end{aligned}$ & $5=$ & Dapat melokalisisr nyeri \\
\hline $3=$ Melokalisasi nyeri & $4=$ & $\begin{array}{l}\text { Withdraw (menghindar/ } \\
\text { menarik ektremitas atau tubuh menjauhi stimulus } \\
\text { saat }\end{array}$ \\
\hline $2=$ Memberi respon fleksi pada rangsang nyeri & $3=$ & dirangsang nyeri) \\
\hline $1=$ Respon ekstensi & $2=$ & Menjauhi rangsang nyeri \\
\hline $\begin{aligned} 0= & \text { Tidak ada respon terhadap nyeri atau status } \\
& \text { mioklonus umum }\end{aligned}$ & $1=$ & $\begin{array}{l}\text { Ekstensi Spontan } \\
\text { Tidak ada respon }\end{array}$ \\
\hline Refleks batang otak & & on Verbal \\
\hline $4=$ Terdapat refleks pupil dan kornea & $5=$ & Orientasi baik \\
\hline $3=$ Salah satu pupil melebar terus menerus & $4=$ & $\begin{array}{l}\text { Bingung, berbicara mengacau, disorientasi tem- } \\
\text { pat dan waktu }\end{array}$ \\
\hline $2=$ Tidak ada refleks pupil atau kornea & $3=$ & $\begin{array}{l}\text { Bisa membentuk kata tetapi tidak bisa memben- } \\
\text { tuk kalimat }\end{array}$ \\
\hline $1=$ Tidak ada refleks pupil dan kornea & $2=$ & Bisa mengeluarkan suara tanpa arti (mengerang) \\
\hline $\begin{array}{l}0=\text { Tidak ada refleks pupil, kornea, atau batuk } \\
\text { Respirasi }\end{array}$ & $1=$ & Tidak bersuara \\
\hline $4=$ Pola nafas regular, tidak diintubasi & & \\
\hline $3=$ Pola cheyne-stokes, tidak diintubasi & & \\
\hline $2=$ Pola nafas iregular, tidak diintubasi & & \\
\hline $\begin{aligned} & 1= \text { Nafas dengan kecepatan di atas ventilator, } \\
& \text { diintubasi }\end{aligned}$ & & \\
\hline $\begin{aligned} 0= & \text { Apnea atau pernafasan dengan kecepatan } \\
& \text { ventilator }\end{aligned}$ & & \\
\hline
\end{tabular}


terdiri dari refleks batang otak, penilaian mata, respon motorik dengan spektrum luas, pola napas abnormal serta usaha napas pada pasien yang menggunakan ventilator, dengan skala penilaian 0-4 untuk masing-masing komponen, dengan skor total terdiri atas 16 poin. ${ }^{8,9}$ FOUR score dianggap lebih baik dibandingkan dengan skala yang telah ada sebelumnya dalam mengklasifikasikan penurunan kesadaran. FOUR score lebih sederhana dan memberikan informasi yang lebih baik, terutama pada pasien-pasien yang diintubasi. Diantara beberapa keunggulan FOUR score dibanding GCS, dimana komponen membuka mata pada FOUR score terdapat 'eye track' sehingga dapat menilai fungsi mesensefalon dan pons. Kemudian pada komponen motorik ditambahkan adanya gerakan tangan spesifik, seperti 'thumbs up, fist, atau peace sign'. Sebagian besar skor motorik mirip dengan GCS, tidak ada perbedaan antara sikap fleksor dan fleksi normal terhadap nyeri. Pada komponen motorik terendah, tidak adanya respons motorik dan status epileptikus myoklonik dimasukkan dalam tingkat yang sama, sehingga mencerminkan outcome buruk setelah terjadi cedera otak. ${ }^{8}$

Penilaian spesifik terhadap refleks batang otak melalui pupil, kornea, dan refleks batuk memungkin kan penilai untuk melokalisasi lesi dan menilai progresifitas cedera otak secara spesifik dan cepat dengan melihat adanya midriasis unilateral, yang merupakan tanda adanya herniasi unkal. Komponen terakhir dari FOUR score adalah pola respirasi. Evaluasi pola pernafasan dinilai sebagai pernafasan spontan reguler, irreguler, pernafasan CheyneStokes, dengan intubasi atau apneu. Pola napas Cheyne-Stokes dan ireguler dapat mencerminkan adanya disfungsi batang otak bagian bawah yang mengendalikan pernapasan, dan dikaitkan dengan prognosis buruk. Pada pasien yang diintubasi, jumlah frekuensi napas yang melebihi frekuensi yang diberikan oleh ventilator menggambarkan masih adanya usaha napas yang berarti masih adanya fungsi pusat pernafasan. Dengan rentang skala penilaian yang sama di tiap-tiap komponen yakni 0-4, maka menjadi lebih mudah diingat. Jika semua 4 komponen dinilai 0 , maka pemeriksa dapat menganjurkan untuk pemeriksaan mati batang otak. ${ }^{10}$ Saat ini FOUR score tidak hanya digunakan pada pasien dengan cedera otak tetapi dapat pula digunakan pada pasien dengan gangguan metabolik akut, syok, atau kerusakan otak non struktural lain karena skala ini dapat mendeteksi perubahan kesadaran lebih dini. Beberapa penelitian telah membandingkan penggunaan FOUR score dan GCS dalam memprediksi mortalitas dan outcome pada pasien cedera otak dan pasien kritis lainnya. ${ }^{11}$

\section{Pembahasan}

Skala koma yang ideal seharusnya linear (memiliki bobot yang sama bagi setiap komponen), reliabel (mengukur yang seharusnya diukur), valid (menghasilkan nilai yang sama pada pemeriksaan berulang), dan mudah digunakan (memiliki instruksi yang simpel tanpa memerlukan alat bantu atau kartu). Selain itu skala koma harus dapat memprediksi luaran walaupun angka kematian di ruang rawat intensif dapat dipengaruhi oleh salah satunya adanya bantuan hidup pada pasien kritis. ${ }^{12-15}$ Penelitian yang dilakukan selama ini menunjukkan tidak adanya perbedaan nilai total dari pemeriksaan yang dilakukan oleh perawat, residen, ataupun dokter baik untuk FOUR score maupun GCS. Penelitian lainnya membuktikan tidak adanya perbedaan antara nilai total antara perawat, residen, atau dokter, baik dalam penggunaan FOUR score $(\mathrm{p}=0,777)$, ataupun GCS $(\mathrm{p}=0,125) .{ }^{15}$ Hal ini juga disampaikan dalam studi lainnya bahwa reliabilitas FOUR score dan GCS dinilai cukup baik, baik pada kelompok yang belum ataupun telah terlatih. ${ }^{16}$ Sebuah riset mengklaim mendapatkan kesesuaian pada penggunaan FOUR score mencapai 0,882 dan pada GCS 0,862 , dengan koefisien korelasi intrakelas berturut-turut 0,975 dan $0,964.13$ Di Indonesia, telah dilaporkan reliabilitas keseluruhan penilai pada FOUR score (FOUR $0,963 ; 0,890 ; 0,845)$ lebih baik daripada GCS (GCS 0,$851 ; 0,740 ; 0,700)$ pada penelitian yang dilakukan untuk memprediksi mortalitas pada pasien kritis anak yang dirawat di unit perawatan intensif anak sebuah rumah sakit rujukan pusat. ${ }^{12}$

Penelitian deskriptif yang dilakukan pada 69 


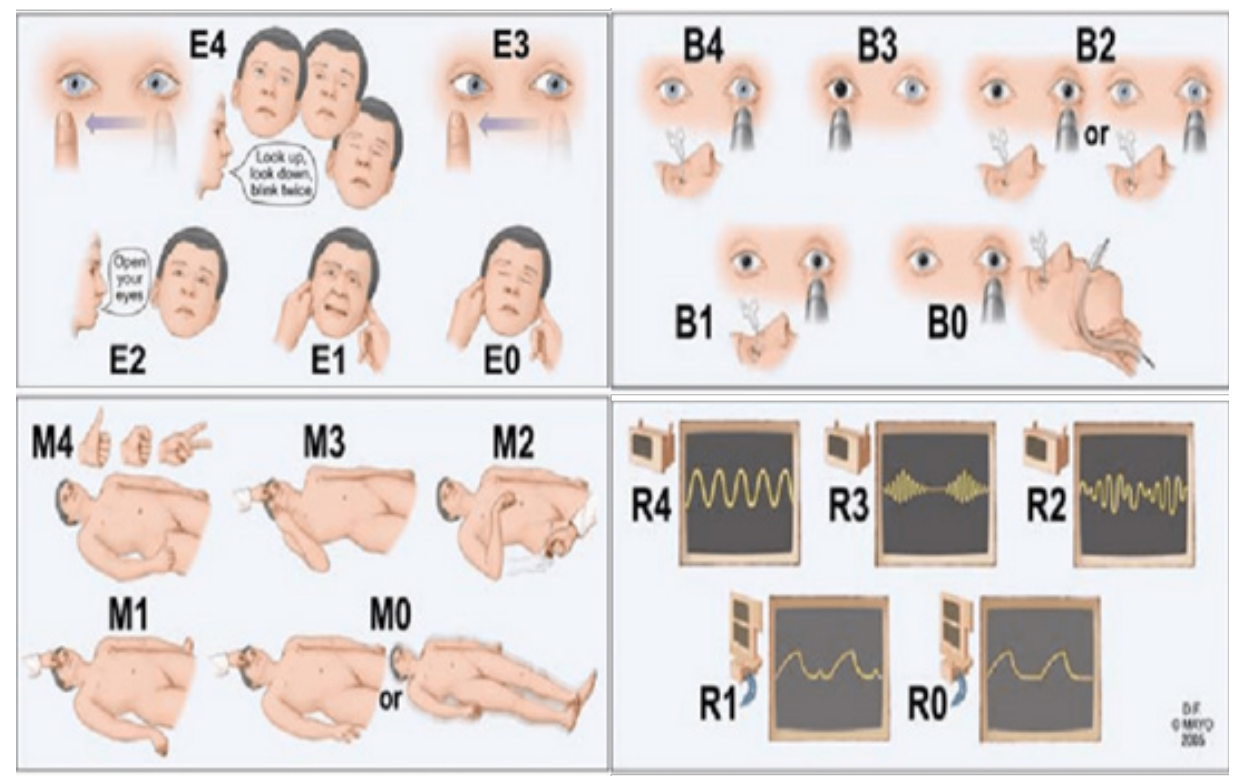

Gambar 1. Komponen Penilaian FOUR Score ${ }^{16}$

pasien yang dirawat di bangsal bedah umum dan bedah saraf dengan cedera otak traumatik di India melaporkan adanya korelasi yang signifikan secara statistik antara FOUR score dan GCS (Glasgow Coma Scale) dalam memperkirakan tingkat keparahan cedera kepala. Selain itu FOUR score mampu memberikan rincian yang lebih baik tentang status neurologis pasien trauma kepala. ${ }^{6}$ Dalam penelitian ini disimpulkan bahwa FOUR score dapat diterapkan sebagai alat yang ideal untuk mengevaluasi tingkat kesadaran dan status neurologis pasien pada pasien dengan cedera otak traumatis dan dapat digunakan dalam 24 jam pertama sejak pasien dirawat. ${ }^{6}$ Peneliti juga mengungkapkan bahwa FOUR score memiliki daya prediksi yang tinggi dalam menentukan luaran pada waktu pemulangan untuk pasien dengan cedera otak traumatik. ${ }^{6}$ Peneliti lain dari Taiwan melakukan penelitian retrospektif pada 55 pasien yang dirawat di unit rawat intensif dengan cedera otak traumatik. Peneliti membandingkan FOUR score, GCS, dan APACHE II untuk memprediksi mortalitas dan luaran pada pasien cedera otak dan pada penelitian ini didapatkan FOUR score merupakan skala yang valid dan sederhana yang sebanding dengan GCS dan APACHE II dalam memprediksi luaran pada pasien cedera otak traumatik. Selain itu, skala ini mengatasi beberapa kekurangan yang ada pada GCS dan mudah dilakukan pada pasien yang diintubasi. ${ }^{14}$ Tidak hanya pada populasi dewasa, sebuah penelitian di Turki menemukan bahwa pada penelitian yang membandingkan kemampuan prognosis GCS dan FOUR score pada 100 orang pasien anak dengan cedera otak traumatik didapatkan FOUR score lebih baik dalam memprediksi kematian di rumah sakit meskipun perbedaan yang didapatkan tidak signifikan. Penelitian ini juga menemukan hubungan moderat antara FOUR score dengan Glasgow Outcome Scale (GOS). ${ }^{3}$ Peneliti lain dari Indonesia juga menyimpulkan bahwa prediksi prognostik pada pasien yang dirawat di unit perawatan intensif anak dengan FOUR score lebih baik dibandingkan menggunakan GCS. ${ }^{12}$ Nilai sensitivitas, spesifisitas, nilai prediksi positif dan negatif negatif $93 \%, 86 \%, 88 \%$, dan $92 \%$, serta rasio kemungkinan positif sebesar $6,6 .{ }^{12}$

Banyak peneliti lain menunjukkan nilai prognostik yang sama atau lebih tinggi dari FOUR score dalam memprediksi kematian dimana AUC ROC $=0,788$ untuk FOUR score (95\% CI 0,722$0,844)$ dan AUC ROC $=0,735$ untuk GCS $(95 \%$ CI $0,655-0,797)$ dalam memprediksi mortalitas di rumah sakit $(p=0,0001) .11$ Demikian pula riset lainnya yang menunjukkan $\mathrm{OR}=0,67$ untuk 
FOUR score $(95 \%$ CI $0,53-0,84)$ dibandingkan $\mathrm{OR}=0,68$ untuk GCS $(95 \%$ CI $0,56-0,83)$ dalam memprediksi mortalitas di rumah sakit ( $\mathrm{p}<0,001) .{ }^{13}$ Sebuah penelitian di rumah sakit pemerintah di Kota Surabaya mendapatkan FOUR score mempunyai sensitivitas dan spesifisitas yang lebih baik (sensitivitas $94,4 \%$ dan spesifisitas 96,2\%) daripada GCS (sensitivitas $88,9 \%$ dan spesifisitas 91,4\%) untuk memprediksi kematian pada pasien cedera otak traumatik. Peneliti tersebut mendapatkan nilai sensitivitas dan spesifisitas FOUR score pada titik potong nilai 9 adalah $93 \%$ dan $86 \%$. Hasil ini sesuai dengan penelitian sebelumnya yang menentukan titik potong FOUR score dalam menentukan prognosis kematian di rumah sakit adalah 9.17 Secara umum jumlah total FOUR score yang rendah berhubungan dengan kematian saat dalam perawatan dan skala GOS yang rendah dimana berkaitan dengan disabilitas yang terjadi. Probabilitas untuk kematian saat dalam perawatan lebih tinggi pada total FOUR score terendah dibandingkan dengan total GCS terendah. . $^{611,16,17}$ Hal ini juga sesuai dengan yang disampaikan penelitian di Kanada dalam sebuah systematic review yang menelaah lebih dari 55 artikel tentang FOUR score dan GCS sebagai prediktor luaran dan mortalitas pada pasien dengan cedera otak traumatik dan sakit kritis. FOUR score telah terbukti dapat menjadi prediktor yang baik dalam menentukan luaran (outcome) pada pasien dengan penurunan tingkat kesadaran dan juga menunjukkan reliabilitas antar penilai yang baik di antara dokter dan perawat. ${ }^{2}$

\section{Simpulan}

FOUR score dari berbagai penelitian yang telah dilakukan, terbukti memiliki validitas, reliabilitas, dan kesesuaian yang cukup baik. Empat komponen yang terkandung dalam FOUR score memberikan rincian informasi dari pemeriksaan neurologis seperti refleks batang otak dan pergerakan mata. FOUR score lebih sederhana dan memberikan informasi yang lebih baik, terutama pada pasien yang diintubasi, sehingga direkomendasikan untuk dapat digunakan sebagai alternatif dalam memprediksi luaran dan mortalitas pada pasien dengan cedera otak traumatik.

\section{Daftar Pustaka}

1. Okasha AS, Fayed AM, Saleh AS. The FOUR score predicts mortality, endotracheal intubation and ICU length of stay after traumatic brain injury. Neurocrit Care. 2014;21(3):496-504.

2. Almojuela A, Hasen M, Zeiler FA. The Full Outline of UnResponsiveness (FOUR) score and Its Use in Outcome Prediction: A Scoping Systematic Review of the Adult Literature. Neurocrit Care. 2019;31(1):162-75.

3. Buyukcam F, Kaya U, Karakilic ME, Cavus UY, Turan Sonmez F, Odabas O. Predicting the outcome of children with head trauma: Comparison of FOUR score and GCS. Turkish J Trauma Emerg Surg. 2012;18(6):469-73.

4. Chen B, Grothe C, Schaller K. Validation of a new neurological score (FOUR Score) in the assessment of neurosurgical patients with severely impaired consciousness. Acta Neurochir (Wien). 2013;155(11):2133-9.

5. Kasprowicz M, Burzynska M, Melcer T, Kübler A. A comparison of the Full Outline of UnResponsiveness (FOUR) score and Glasgow Coma Score (GCS) in predictive modelling in traumatic brain injury. $\mathrm{Br} \mathrm{J}$ Neurosurg. 2016;30(2):211-20.

6. Nair SS, Surendran A, Prabhakar RB, Chisthi MM. Comparison between FOUR score and GCS in assessing patients with traumatic head injury: a tertiary centre study. Int Surg J. 2017;4(2):656-662.

7. Ghelichkhani P, Esmaeili M, Hosseini M, Seylani K. Glasgow Coma Scale and FOUR Score in Predicting the Mortality of Trauma Patients; a Diagnostic Accuracy Study. Emerg (Tehran, Iran). 2018;6(1):e42.

8. Idrovo FLA. The FOUR score: is it just another new coma scale? Intern Emerg Med. 
2012;7(3):203-4.

9. Cohen J. Interrater reliability and predictive validity of the FOUR score coma scale in a pediatric population. J Neurosci Nurs. 2009;41(5):261-7.

10. Madjid AS, Tantri A, Simamora M. Combination of Glasgow Coma Scale, Age, and Systolic Blood Pressure in Assessing Patients' Outcomes with Decreased Consciousness. eJournal Kedokt Indones. 2017;5(1):44-49.

11. Eken C, Kartal M, Bacanli A, Eray O. Comparison of the Full Outline of Unresponsiveness Score Coma Scale and the Glasgow Coma Scale in an emergency setting population. Eur $\mathrm{J}$ Emerg Med. 2009;16(1):29-36.

12. Dewi R, Mangunatmadja I, Yuniar I. Perbandingan Full Outline of Unresponsiveness Score dengan Glasgow Coma Scale dalam menentukan prognostik pasien sakit kritis. Sari Pediatr. 2016;13(3):215-20.

13. Stead LG, Wijdicks EFM, Bhagra A, Kashyap R, Bellolio MF, Nash DL, et al. Validation of a New Coma Scale, the FOUR Score, in the Emergency Department. Neurocrit Care. 2009; 10(1):50-4.

14. Nyam T-TE, Ao K-H, Hung S-Y, Shen M-L, Yu T-C, Kuo J-R. FOUR Score Predicts Early Outcome in Patients After Traumatic Brain Injury. Neurocrit Care. 2017;26(2):225-31.

15. Wijdicks EFM, Bamlet WR, Maramattom B V., Manno EM, McClelland RL. Validation of a new coma scale: The FOUR score. Ann Neurol. 2005;58(4):585-93.

16. Khajeh A, Fayyazi A, Miri-Aliabad G, Askari $\mathrm{H}$, Noori N, Khajeh B. Comparison between the Ability of Glasgow Coma Scale and Full Outline of Unresponsiveness Score to Predict the Mortality and Discharge Rate of Pediatric Intensive Care Unit Patients. Iran J Pediatr. 8 Oktober 2014;24(5):603-8.

17. Hamzah, Santosa DA, Subiantoro A. Perbandingan Full Outline of Unresponsiveness Score dengan Glasgow Coma Scale dalam Memprediksi Mortalitas dan Luaran Pasien Cedera Otak Traumatika Berdasarkan Skala Glasgow Outcome Scale. Surabaya: Universitas Airlangga; 2020. 